\title{
Consanguineous marriages
}

\author{
Preconception consultation in primary health care settings
}

\author{
Hanan Hamamy
}

Received: 26 July 2011 / Accepted: 9 November 2011 /Published online: 22 November 2011

(C) Springer-Verlag 2011

\begin{abstract}
Consanguinity is a deeply rooted social trend among one-fifth of the world population mostly residing in the Middle East, West Asia and North Africa, as well as among emigrants from these communities now residing in North America, Europe and Australia. The mounting public awareness on prevention of congenital and genetic disorders in offspring is driving an increasing number of couples contemplating marriage and reproduction in highly consanguineous communities to seek counseling on consanguinity. Primary health care providers are faced with consanguineous couples demanding answers to their questions on the anticipated health risks to their offspring. Preconception and premarital counseling on consanguinity should be part of the training of health care providers particularly in highly consanguineous populations.
\end{abstract}

Keywords Consanguinity . Consanguineous marriages . Preconception counseling · Preconception consultation . Premarital counseling $\cdot$ Primary health care

\section{Introduction}

It is estimated that one billion of the current global population live in communities with a preference for consanguineous marriage (Bittles and Black 2010a; Modell and Darr 2002). Consanguineous marriage is traditional and respected in most communities of North Africa, Middle

Special Issue: Genetic aspects of preconception consultation in primary care.

\section{H. Hamamy $(\bowtie)$}

Department of Genetic Medicine and Development,

Geneva University Hospital,

Geneva, Switzerland

e-mail: hananhamamy@yahoo.com
East and West Asia, where intra-familial unions collectively account for $20-50+\%$ of all marriages (Bittles 2011; Hamamy et al. 2011; Tadmouri et al. 2009) [Fig. 1].

Primary health care providers in communities with high consanguinity rates may be confronted by situations where they are asked to provide preconception counseling to consanguineous couples. In such countries and communities where cousin marriages are customary, many young couples nowadays present to health care providers seeking a scientifically sound answer to their questions including: "Will our children be physically or mentally abnormal?" "How can we minimize the risks for having affected children?"

Reports have indicated that there may be inconsistencies in counseling for consanguinity among health care providers (Bennett et al. 1999). It is important that primary health care providers, specifically in highly consanguineous communities, have clear evidence-based guidelines in counseling a consanguineous couple to minimize their risks for having affected offspring. This review aims to portray the definition and current global trends of consanguinity, and propose simple guidelines for preconception counseling related to consanguinity based on published studies of health burden and social benefits of consanguinity. Such data could guide health care providers and help consanguineous couples take informed decisions regarding their reproductive choices.

\section{Definition of consanguinity}

In clinical genetics, a consanguineous marriage is defined as a union between two individuals who are related as second cousins or closer, with the inbreeding coefficient $(F)$ equal or higher than 0.0156 (Bittles 2001), where $(F)$ represents a measure of the proportion of loci at which the offspring of a consanguineous union is expected to inherit identical gene copies from both parents. This includes 


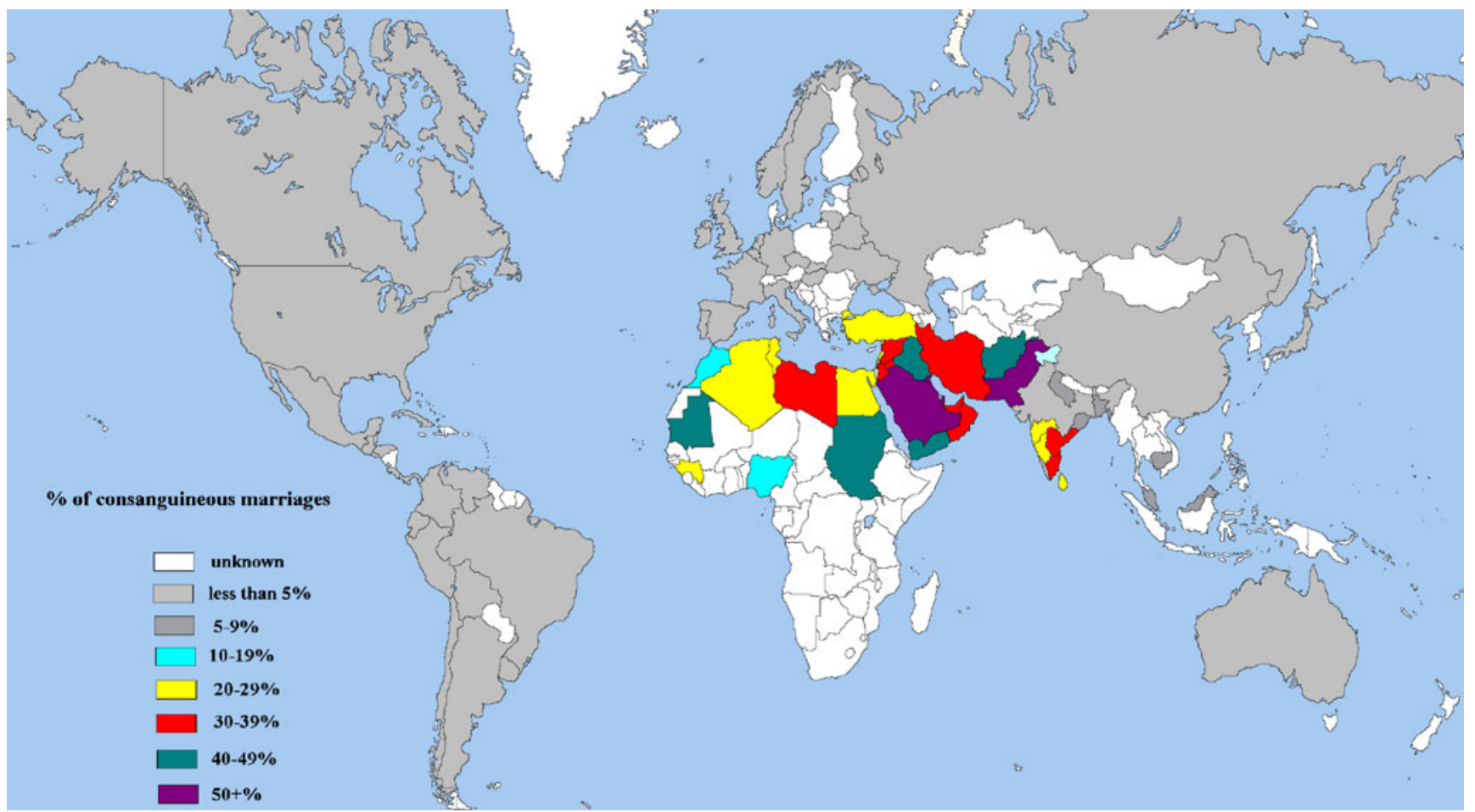

Fig. 1 Global consanguinity rates

unions termed first cousins, first cousins once removed and second cousins. In some communities, the highest inbreeding coefficients are reached with unions between double first cousins practiced among Arabs and uncle-niece marriages practiced in South India where $(F)$ reaches 0.125 (Hamamy et al. 2011) [Fig. 2].
In highly consanguineous populations, pedigrees with complex consanguinity loops arising from cousin marriages in successive generations are encountered leading to higher inbreeding coefficients. Reports on consanguinity rates may sometimes include marriages between third cousins or more distantly related individuals. Although this discrepancy
Fig. 2 Categories of consanguineous marriages

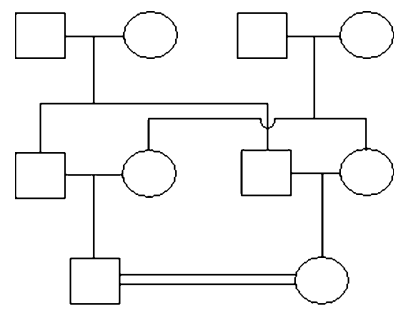

Double First Cousins $F=0.125$

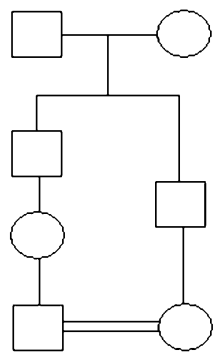

First Cousins once removed $F=0.0313$

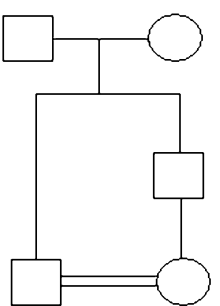

Uncle-niece $F=0.125$

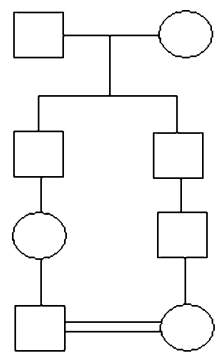

Second Cousins $F=0.0156$

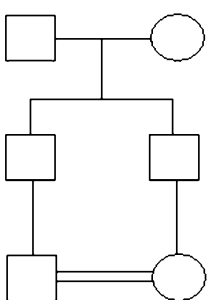

First Cousins $F=0.0625$

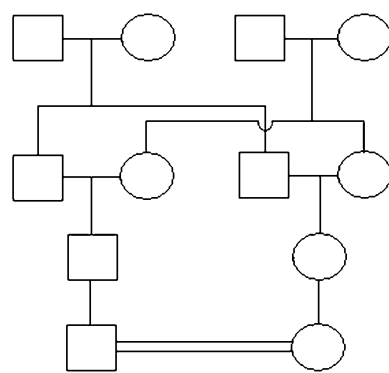

Double Second Cousins $F=0.0313$ 
affects the total consanguinity rate, the lower coefficients of inbreeding in more remote unions limit a marked alteration of the mean inbreeding coefficient $(\alpha)$. To report and compare consanguinity rates among different populations, the two parameters best used are the mean inbreeding coefficient and the rates of marriages between first cousins.

\section{Global consanguinity trends}

In populations of North Africa, West Asia and South India, consanguineous marriages are culturally and socially favoured and constitute $20-50 \%$ of all marriages [Fig. 1], with first cousins unions accounting for almost one-third of all marriages (Bittles 2011; Tadmouri et al. 2009). The prevalence of consanguinity and rates of first cousin marriage vary widely within and between populations and communities, depending on ethnicity, religion, culture and geography. Consanguineous marriages are also practised among emigrant communities from highly consanguineous countries and regions, such as Pakistan, Turkey, North Africa and Lebanon, now resident in Europe, North America and Australia (Hamamy et al. 2011; Schulpen et al. 2006).

The high consanguinity rates, coupled by the large family size in some communities, could induce the expression of autosomal recessive diseases, including very rare or new syndromes which increase the public awareness of the risks associated with consanguineous marriages. Currently, many young consanguineous couples planning to have children seek preconception genetic counseling for fear of the consequences of consanguinity on their offspring.

\section{Why are consanguineous marriages culturally favoured?}

The actual reasons given for the preference of consanguineous marriages are primarily social. In communities with high consanguinity rates, sociological studies indicate that consanguineous marriage could enforce the couples' stability due to higher compatibility between husband and wife who share the same social relationships after marriage as before marriage, as well as the compatibility between the couple and other family members.

Consanguineous marriage may be more favourable for the women's status, including the wife's better relationship with her in-laws who could support her in time of need. There is a general belief that marrying within the family reduces the possibilities of hidden uncertainties in health and financial issues. It is believed that consanguinity strengthens family ties and enforces family solidarity, with cousin marriage providing excellent opportunities for the transmission of cultural values and cultural continuity (Sandridge et al. 2010). Premarital negotiations regarding financial matters of marriage are more easily conducted and sometimes less costly. Wife's parents prefer to have their daughter living near them and to enjoy the presence of their grandchildren. Moreover, wealthy landlords may prefer to keep their property within the family (Bittles 2001; Hamamy and Bittles 2008).

\section{Consanguinity and health parameters}

Health care providers and genetics specialists could consider both the negative impact of consanguineous marriage in terms of increased genetic risks to the offspring, as opposed to the potential social and economic benefits (Hamamy et al. 2011).

The reproductive health criteria related to consanguinity show that in first cousin marriages as opposed to nonconsanguineous marriages, fertility rate is slightly higher, abortion rate is not different, stillbirths and infant mortality rates are slightly higher and birth defects frequency is estimated to be around $2-3 \%$ points more than the background rate among newborns in the general population (around 2-3\%). Furthermore, consanguineous unions lead to increased expression of autosomal recessive disorders (Bittles et al. 1991; Bittles and Black 2010b; Hamamy et al. 2011; Tadmouri et al. 2009). The offspring of consanguineous unions may be at increased risk for recessive disorders because of the expression of autosomal recessive gene mutations inherited from a common ancestor. The closer the biological relationship between parents, the greater is the probability that their offspring will inherit identical copies of one or more detrimental recessive genes. For example, first cousins are predicted to share $12.5 \%(1 / 8)$ of their genes. Thus, on average, their progeny will be homozygous at $6.25 \%(1 / 16)$ of gene loci (Bennett et al. 2002).

In general, consanguinity does not increase the risk for autosomal dominant conditions in offspring when one of the parents is affected, nor for $\mathrm{X}$-linked recessive conditions if neither parent is affected (Hamamy et al. 2007b).

Most of the literature studying the association of Down syndrome with parental consanguinity concluded that no such association existed. The association of consanguineous marriages with late onset complex diseases such as diabetes, cardiovascular disorders, schizophrenia and cancer requires further studies to precise any existing risks because currently unambiguous evidence-based conclusions are difficult to establish (Hamamy et al. 2011).

\section{Preconception and premarital counseling for consanguinity}

Preconception genetic counseling for consanguinity is considered one of the important pillars amongst the 
community genetic services in highly consanguineous populations. Premarital counseling is another increasingly demanded service in some countries and communities where consanguinity rates are still high and selective abortion of affected fetus is not feasible and/or not acceptable. Marriage in many such countries is regarded as a family decision and not just the couple's decision, although the frequency of "arranged marriages" may be declining in recent years due to the increasing number of females reaching university level education which gives them a broader choice of marriage partner. Many marriages, whether both interfamilial and intrafamilial (consanguineous), are however still considered arranged marriages in some communities. The term "arranged marriage" does not mean that the marriage is planned against the will or acceptance of either partner, but it basically implies that a certain suitable couple is given the option of getting married under the family supervision. Among marriages contracted from 1969 to 1979 in Jordan, $73.3 \%$ of 1983 marriages were arranged through parents' agreement first and then couples' consent, while in $18.6 \%$, the marriage was through the couples' agreement first then the parents' consent (Khoury and Massad 1992).

In populations with high consanguinity rates and common inherited blood disorders, community programs for premarital screening to detect carriers of hemoglobinopathies such as thalassemia and sickle cell anemia are in progress as for example in Jordan (Hamamy et al. 2007a), Saudi Arabia (Memish and Saeedi 2011), Iran (Fallah et al. 2009), Iraq (Al-Allawi and Al-Dousky 2010), Bahrain (Al-Arrayed 2005) and Turkey (Mendilcioglu et al. 2011). Carrier detection and genetic counseling programs have been very successful in reducing the birth prevalence of inherited disorders in some populations, such as in Iran (Khorasani et al. 2008; Samavat and Modell 2004). These programs are most successful when they are sensitive to the cultural backgrounds of populations in which they are applied. In Saudi society, although premarital screening to identify carrier status and the provision of appropriate counseling has tremendous potential to prevent inherited disease (Meyer 2005), results from a screening program for sickle cell disease and $\beta$-thalassemia indicated that about $90 \%$ of couples in Saudi Arabia at risk of having affected children still decided to marry because of fear of social stigmatisation and/or because wedding plans could not be cancelled, which emphasizes the need to conduct premarital screening well in advance of the wedding. One option to be explored is the introduction of screening during secondary school (Alswaidi et al. 2011).

In addition to their primary goals, premarital screening programs in some communities have helped in raising the public's awareness of genetic diseases in general, their prevention possibilities and the fear that consanguinity is a risk factor for expression of recessive disorders, which has led to an increase in numbers of couples seeking premarital and preconception counseling for consanguinity.

In countries such as Tunisia, premarital genetic counseling is obligatory for all couples with a history of genetic complications and in cases of consanguinity (ChaabouniBouhamed 2008). Premarital counseling is also frequent in some countries offering population-based genetic counseling. For example, in Shiraz, southern Iran, among 2,686 couples presenting for genetic counseling during a 4-year period, data files revealed that $85 \%$ had consanguineous relationships ( $74 \%$ were first cousins). Most prevalent reasons for referral were premarital counseling $(80 \%)$, with $89 \%$ consanguinity. Premarital genetic counseling poses unique challenges and opportunities in such countries where the tradition of consanguinity is likely to persist (Fathzadeh et al. 2008).

Preconception carrier screening for hemoglobinopathies is debated in the Netherlands, a country with immigrants from populations known to have high rates of hemoglobinopathies and high consanguinity rates. A study assessing the intentions to participate in preconception carrier screening for hemoglobinopathies among Turkish female immigrants reported that of the 109 women enrolled in the study, $83.5 \%$ would participate in preconception carrier screening, if it was offered. Although the acceptability of preconception carrier screening was high, the degree of acceptability of prenatal testing and termination of affected pregnancies was relatively low (van Elderen et al. 2010).

Proposed steps in preconception counseling for a consanguineous couple

In offering preconception counseling for consanguinity, it is crucial to distinguish between families with a known genetic or inherited disorder and those with no known such disorder by taking a detailed family history and constructing a four-generation pedigree (including offspring, siblings, parents, grandparents, aunts, uncles, nieces, nephews and first cousins of the consultand or proband) (Fig. 3) (Bennett et al. 2002). Reports have shown that in certain clinical settings, practice guidelines regarding collecting information on consanguinity as part of family history are not available, despite the relevance of such history in identifying at-risk pregnancies (Bishop et al. 2008). Specific questions addressed to the couple could help in eliciting the presence of a genetic or hereditary disorder in the extended family. These could include inquiry about the presence of any of the following in blood relatives:

- Birth defects or congenital anomalies

- Early hearing impairment

- Early vision impairment 


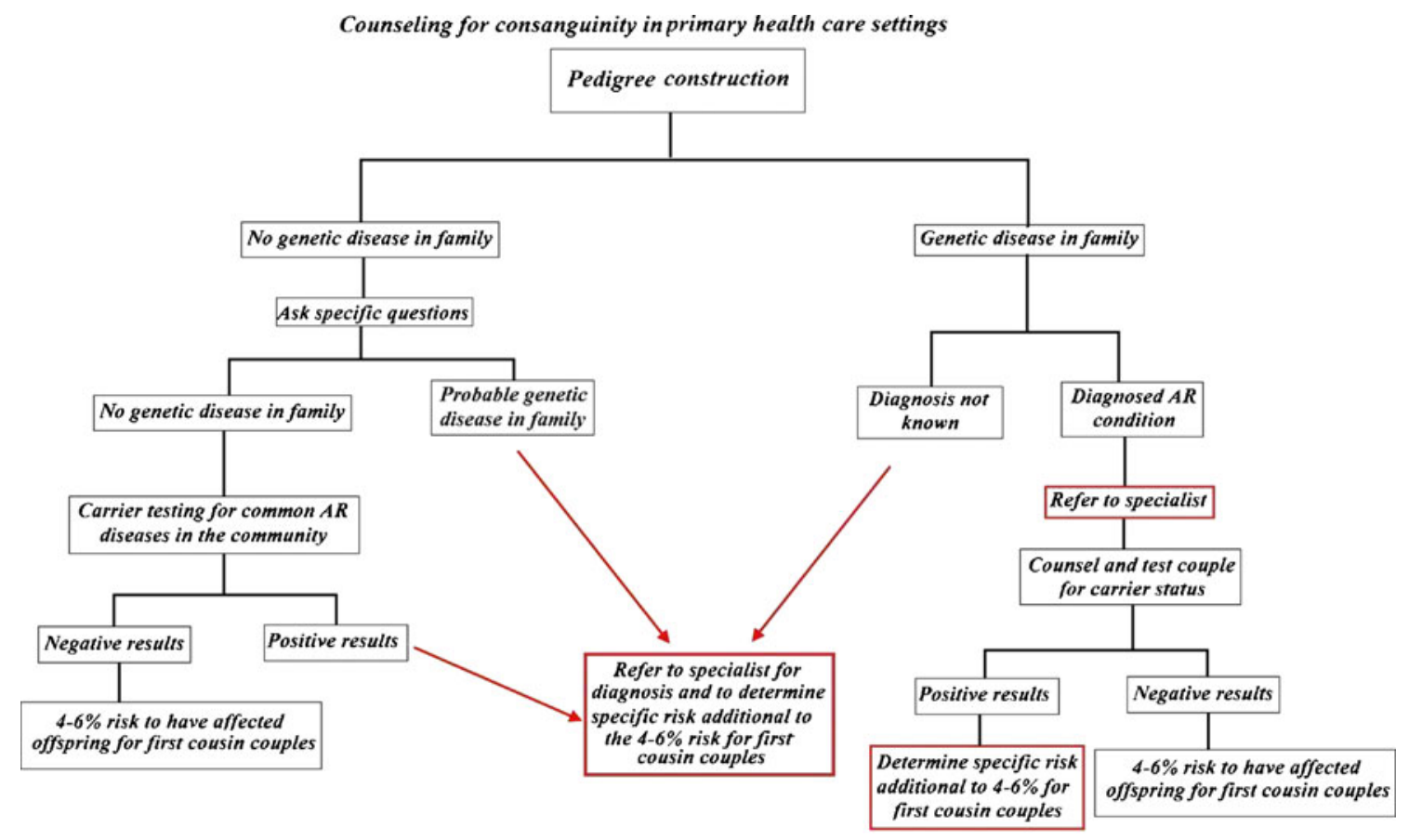

Fig. 3 Steps in preconception counseling for a consanguineous couple

- Mental retardation or learning disability

- Developmental delay or failure to thrive

- Inherited blood disorder

- Unexplained neonatal or infant death in offspring

- Epilepsy

- Undiagnosed severe condition

In families with hearing, vision or mental disabilities, informative family history coupled by clinical data and investigations could differentiate cases that are associated with consanguinity from cases caused by other factors.

If there is no known genetic disorder in the family, first cousin marriages are generally given a risk for birth defects in the offspring that is double the population risk (Stoltenberg et al. 1997) (for example, instead of $2.5 \%$, it becomes $5 \%$ ), or the risk may be given as $1.7-2.8 \%$ higher than the population background risk, mostly attributable to autosomal recessive diseases (Bennett et al. 1999, 2002; Tadmouri et al. 2009; Zlotogora and Shalev 2010). Closer consanguineous relationship such as a double first cousins couple may be given a higher risk for their offspring which may be estimated at triple the rate of birth defects in the general population (Christianson et al. 2006). Couples who are more distantly related could have a similar risk of birth defects in their offspring as first cousin couples in highly inbred populations. This may be due to the fact that in such inbred populations the actual relationship coefficient among two individuals is much higher than the one calculated based on information given by the couple
(Zlotogora 2002). On the other hand, among non-inbred general population, the risk to offspring of a couple related more distantly than first cousins could be close to that of a non-related couple (Stoltenberg et al. 1997). It also appears that the offspring of first cousin marriages are not at an increased risk for birth defects in their children if they are married to a non-relative (Zlotogora 2005).

The higher risk for infant mortality could be mentioned to the couple, although practically speaking, it is very difficult for the counselor to give the accurate percentage because the risk depends on the general population parameters which are not always known. Multinational studies among first cousin progeny indicated that there is a mean of $1.1 \%$ excess infant deaths over that of the nonconsanguineous progeny (Bittles and Black 2010b), with an equivalent excess of $3.5 \%$ in pre-reproductive mortality (Bittles and Black 2010a). Individual studies can give different risk figures dictated by various factors, including factors inherent to the studied populations. For example, in Norway, the risk of stillbirth and infant deaths among first cousin couples was 1.7 times that for unrelated parents (Stoltenberg et al. 1999).

If family history points to the presence of a genetic disorder, then primary health care providers could refer the couple to a specialized genetic counseling clinic. This helps in estimating the precise risks to the offspring and in diagnosing their carrier status for autosomal recessive disorders known to be present in the family whenever such tests are feasible and applicable. 
When a consanguineous couple presents to the genetic counseling clinic because they know that they have a genetic disorder in their family, a stepwise procedure is attempted starting with construction of a pedigree and taking a detailed family history. Several reports have emphasized the importance of constructing an extended family tree (usually three generations) as a tool to discover genetic diseases in the family (World Health Organization 2010), and in some cases to elicit the modes of inheritance. If the condition follows an autosomal recessive mode of inheritance, accurate clinical and molecular diagnosis in the affected is attempted whenever feasible. If the molecular diagnosis is reached, the couple can be tested for carrier status of the condition. Difficulties arise at this step when the affected cannot be reached, refuses testing or is deceased, with the consequence of inability to reach an accurate diagnosis to test the couple for carrier status. In this case, the couple is given estimates for their risks of having an affected child based on the pedigree. This scenario may not suffice the couple who request a direct advice from the counselor on how to minimise their risks for having an affected child. According to the principles of genetic counseling, it is expected that the counselor remains neutral, a position that may not satisfy the couple. Genetic counselors, although frequently asked what they themselves would do if placed in the consultand's position, should avoid being drawn into expressing an opinion.

If the disorder in the family indicates that it is following an autosomal dominant mode of inheritance, the risks to offspring of non-affected parents are very low, estimated according to the frequency of non-penetrance of the disorder. When the father is not affected by an Xlinked recessive disorder propagating in the family, consanguinity does not increase the risk for having a child with such disorder. If the father is affected by a condition such as G6PD deficiency which is a common $\mathrm{X}$-linked disorder in the Middle East, consanguinity among the couple with probability that the wife is also a carrier of the same gene increases the risk for having affected daughters.

Complex disorders such as hypertension, coronary artery disease, diabetes, schizophrenia, autism and cancer are aetiologically heterogeneous, with multifactorial inheritance suspected in most families and cases. High susceptibility genes could play a significant role in the expression of a complex disease, and if such genes are rare and transmitted in an autosomal recessive manner then consanguinity could be a determinant factor. Among highly consanguineous populations, little has been published on the effects of consanguinity on the complex late-onset disorders that account for most of the public health burden (Bittles and Black 2010a). However, in some families with multiple affected members and multiple consanguineous marriages, the condition could be associated with consanguinity if there is a high susceptibility gene present in the family. Precise risks are usually difficult to estimate in individual cases.

In communities where arranged marriages are still practiced, some families with propagating autosomal recessive conditions that are not amenable to carrier detection request counseling on further intermarriages. The decision on limiting such marriages still faces many problems, and it usually involves members in the family who do not welcome admitting that the family has a "hereditary disorder" for fear of stigmatisation within the family and within a society with low genetic literacy.

Problems can also arise if the disorder in question shows genetic heterogeneity, such as hearing impairment and nonspecific mental retardation. In these situations empiric risks can be used which are sometimes not satisfactory to the family. New technologies including next generation sequencing could eventually help in diagnosing patients affected by conditions known to be genetically heterogeneous. Moreover, such technologies could diagnose if both couple carry the same autosomal recessive gene that causes a severe disorder (Bell et al. 2011). It is envisaged that such technology could in the future become feasible and affordable to screen for carrier status and would markedly reduce the risks for consanguineous couples to have offspring affected by serious autosomal recessive disorders.

In populations that are highly endogamous, genetic counseling and screening could be offered with consideration of the genetic disorders that occur with higher frequency in that specific population (Bennett et al. 2002). Genetic screening and counseling programs at different levels of health care have been initiated in some high-risk communities. For example, in an isolated Druze village in Israel, where consanguinity rate is high, couples were screened for four rare inherited diseases that showed a high carrier frequencies among residents with identification of ten at risk couples (Falik-Zaccai et al. 2008). Among the Persian Jewish community of greater Los Angeles, four relatively frequent autosomal recessive conditions were screened for, with identification of ten at risk couples (Kaback et al. 2010). Similar screening projects can be programmed whenever an inbred community proves to have high frequency of specific recessive disorders.

Social and educational barriers in counseling for consanguinity

In some communities, organizational and social barriers prevent collecting information about consanguinity in primary health care settings and in midwifery practice, restricting identification of at-risk pregnancies (Bishop et al. 2008). 
The belief that inherited disorders can only arise through cousin marriages on the paternal side of the family is also quite common, and in the minds of many people consanguinity may refer only to paternal blood relationships. Thus, during counseling, if a couple indicate that they are not related, it is imperative to specifically inquire about any shared biological relationships on their mothers' sides of the families. In similar vein, families may opt to avoid cousin marriages when the disease is inherited as autosomal dominant and are bewildered and confused by the subsequent birth of an affected baby (Bittles and Hamamy 2010).

Among British Pakistanis, some patients had assimilated genetic information in ways that conflict with genetic theory with potentially serious clinical consequences. Patients referred to genetics clinics may not easily surrender their lay or personal theories about the causes of their own or their child's condition and their understandings of genetic risk (Shaw and Hurst 2008) including the risks of cousin marriages.

Education of the public in general and of primary health personnel in particular is an important pillar in clarifying the health and social effects of consanguineous marriages.

The balance between the possible biological risks of consanguinity and the social benefits including the nonstigmatisation of the female partner in a society with minimal genetic literacy could vary among different couples and different settings. In rural communities, the social benefits of consanguineous marriages could outweigh their impact on health and vice versa in urban communities (Bittles and Black 2010a). A point that draws much debate is whether clear guidelines can be adopted in certain situations where counselors are allowed to advice rather than just give risk estimates.

\section{Conclusion}

Consanguinity is a deeply rooted social trend with one billion people currently living in countries where consanguineous marriages are customary, and among them, one in every three marriages is between cousins. The rising public awareness on possible preventive measures for congenital disorders has led to an augmentation in the number of couples seeking preconception and premarital counseling on consanguinity.

Consanguineous marriages are associated with an increased risk for congenital malformations and autosomal recessive diseases, with some resultant increased postnatal mortality in the offspring of first cousin couples, but demographic and socioeconomic confounders need to be well controlled. No major adverse associations with reproductive parameters such as miscarriages and fertility have been documented. Associations with quantitative traits and complex adult-onset diseases are vague and inconsistent, suggesting the importance of implementing future research in this area.

To standardize genetic services, guidelines for screening consanguineous couples and their offspring are needed. Consideration could be given to screening based on common autosomal recessive conditions in the populations and communities.

In both high and low income countries, there is a capacity to provide health education for consanguinity at individual, family and community levels delivered by primary health care personnel with preconception and premarital genetic counseling, and diagnosis. Rather than discouraging consanguineous marriages in populations with long-held such tradition, ensuring access to preconception and premarital counseling services is the logical way to proceed and more likely both to receive community acceptance and be successful in maintaining and improving health (Alwan and Modell 1997; Bittles 2009). Increasing public literacy on consanguinity could be achieved by providing proper education and training to primary health care workers on all health and social issues related to consanguinity.

Conflict of interest The author declares that she has no conflict of interest.

\section{References}

Al-Allawi NA, Al-Dousky AA (2010) Frequency of haemoglobinopathies at premarital health screening in Dohuk, Iraq: implications for a regional prevention programme. East Mediterr Health J 16:381-385

Al-Arrayed S (2005) Campaign to control genetic blood diseases in Bahrain. Community Genet 8:52-55

Alswaidi FM, Memish ZA, O'Brien SJ, Al-Hamdan NA, Al-Enzy FM, Alhayani OA, Al-Wadey AM (2011) At-risk marriages after compulsory premarital testing and counseling for betathalassemia and sickle cell disease in Saudi Arabia, 2005-2006. $\mathrm{J}$ Genet Couns

Alwan A, Modell B. Community control of genetic and congenital disorders. EMRO Technical Publication Series 24: WHO Regional Office for the Eastern Mediterranean Region, Egypt. 1997

Bell CJ, Dinwiddie DL, Miller NA, Hateley SL, Ganusova EE, Mudge J, Langley RJ, Zhang L, Lee CC, Schilkey FD, Sheth V, Woodward JE, Peckham HE, Schroth GP, Kim RW, Kingsmore SF (2011) Carrier testing for severe childhood recessive diseases by next-generation sequencing. Sci Transl Med 3:65ra4

Bennett RL, Hudgins L, Smith CO, Motulsky AG (1999) Inconsistencies in genetic counseling and screening for consanguineous couples and their offspring: the need for practice guidelines. Genet Med 1:286-292

Bennett R, Motulsky A, Bittles A et al (2002) Genetic counseling and screening of consanguineous couples and their offspring: recommendations of the National Society of Genetic Counselors. J Genet Couns 11(2):97-119 
Bishop M, Metcalfe S, Gaff C (2008) The missing element: consanguinity as a component of genetic risk assessment. Genet Med 10:612-620

Bittles A (2001) Consanguinity and its relevance to clinical genetics. Clin Genet 60:89-98

Bittles AH (2009) Commentary: the background and outcomes of the first-cousin marriage controversy in Great Britain. Int J Epidemiol 38:1453-1458

Bittles A. The global prevalence of consanguinity. http:/www. consang.net accessed June 2011. 10-12-2011

Bittles AH, Black ML (2010a) Evolution in health and medicine Sackler colloquium: consanguinity, human evolution, and complex diseases. Proc Natl Acad Sci U S A 107(Suppl 1):1779-1786

Bittles AH, Black ML (2010b) The impact of consanguinity on neonatal and infant health. Early Hum Dev 86:737-741

Bittles A, Hamamy H (2010) Endogamy and consanguineous marriage in Arab populations. In: Teebi A (ed) Genetic disorders among Arab populations, 2nd edn. Springer, Heidelberg

Bittles AH, Mason WM, Greene J, Rao NA (1991) Reproductive behavior and health in consanguineous marriages. Science 252:789-794

Chaabouni-Bouhamed H (2008) Tunisia: communities and community genetics. Community Genet 11:313-323

Christianson A, Howson C, Modell B (2006) Global report on birth defects. The hidden toll of dying and disabled children. March of Dimes Birth Defects Foundation, White Plains

Falik-Zaccai TC, Kfir N, Frenkel P, Cohen C, Tanus M, Mandel H, Shihab S, Morkos S, Aaref S, Summar ML, Khayat M (2008) Population screening in a Druze community: the challenge and the reward. Genet Med 10:903-909

Fallah MS, Samavat A, Zeinali S (2009) Iranian national program for the prevention of thalassemia and prenatal diagnosis: mandatory premarital screening and legal medical abortion. Prenat Diagn 29:1285-1286

Fathzadeh M, Babaie Bigi MA, Bazrgar M, Yavarian M, Tabatabaee HR, Akrami SM (2008) Genetic counseling in southern Iran: consanguinity and reason for referral. J Genet Couns 17:472-479

Hamamy H, Bittles AH (2008) Genetic clinics in Arab communities: meeting individual, family and community needs. Public Health Genomics Sep 3. [Epub ahead of print]

Hamamy H, Al-Hait S, Alwan A, Ajlouni K (2007a) Jordan: communities and community genetics. Community Genet 10:52-60

Hamamy HA, Masri AT, Al-Hadidy AM, Ajlouni KM (2007b) Consanguinity and genetic disorders. Profile from Jordan. Saudi Med J 28:1015-1017

Hamamy H, Antonarakis SE, Cavalli-Sforza LL, Temtamy S, Romeo G, Ten Kate LP, Bennett RL, Shaw A, Megarbane A, van DC, Bathija H, Fokstuen S, Engel E, Zlotogora J, Dermitzakis E, Bottani A, Dahoun S, Morris MA, Arsenault S, Aglan MS, Ajaz M, Alkalamchi A, Alnaqeb D, Alwasiyah MK, Anwer N, Awwad R, Bonnefin M, Corry P, Gwanmesia L, Karbani GA, Mostafavi M, Pippucci T, Ranza-Boscardin E, Reversade B, Sharif SM, Teeuw ME, Bittles AH (2011) Consanguineous marriages, pearls and perils: Geneva International Consanguinity Workshop report. Genet Med 13:841-847

Kaback M, Lopatequi J, Portuges AR, Quindipan C, Pariani M, Salimpour-Davidov N, Rimoin DL (2010) Genetic screening in the Persian Jewish community: a pilot study. Genet Med 12:628-633
Khorasani G, Kosaryan M, Vahidshahi K, Shakeri S, Nasehi MM (2008) Results of the national program for prevention of betathalassemia major in the Iranian Province of Mazandaran. Hemoglobin 32:263-271

Khoury SA, Massad D (1992) Consanguineous marriage in Jordan. Am J Med Genet 43:769-775

Memish ZA, Saeedi MY (2011) Six-year outcome of the national premarital screening and genetic counseling program for sickle cell disease and beta-thalassemia in Saudi Arabia. Ann Saudi Med 31:229-235

Mendilcioglu I, Yakut S, Keser I, Simsek M, Yesilipek A, Bagci G, Luleci G (2011) Prenatal diagnosis of beta-thalassemia and other hemoglobinopathies in southwestern Turkey. Hemoglobin 35:47-55

Meyer BF (2005) Strategies for the prevention of hereditary diseases in a highly consanguineous population. Ann Hum Biol 32:174-179

Modell B, Darr A (2002) Science and society: genetic counselling and customary consanguineous marriage. Nat Rev Genet 3:225-229

Samavat A, Modell B (2004) Iranian national thalassaemia screening programme. BMJ 329:1134-1137

Sandridge AL, Takeddin J, Al-Kaabi E, Frances Y (2010) Consanguinity in Qatar: knowledge, attitude and practice in a population born between 1946 and 1991. J Biosoc Sci 42:59-82

Schulpen TW, van Wieringen JC, van Brummen PJ, van Riel JM, Beemer FA, Westers P, Huber J (2006) Infant mortality, ethnicity, and genetically determined disorders in The Netherlands. Eur $\mathrm{J}$ Public Health 16:291-294

Shaw A, Hurst JA (2008) "What is this genetics, anyway?" Understandings of genetics, illness causality and inheritance among British Pakistani users of genetic services. J Genet Couns 17:373-383

Stoltenberg C, Magnus P, Lie RT, Daltveit AK, Irgens LM (1997) Birth defects and parental consanguinity in Norway. Am J Epidemiol 145:439-448

Stoltenberg C, Magnus P, Skrondal A, Lie RT (1999) Consanguinity and recurrence risk of stillbirth and infant death. Am J Public Health 89:517-523

Tadmouri GO, Nair P, Obeid T, Al Ali MT, Al Khaja N, Hamamy HA (2009) Consanguinity and reproductive health among Arabs. Reprod Health 6:17

van Elderen T, Mutlu D, Karstanje J, Passchier J, Tibben A, Duivenvoorden HJ (2010) Turkish female immigrants' intentions to participate in preconception carrier screening for hemoglobinopathies in the Netherlands: an empirical study. Public Health Genomics 13:415-423

World Health Organization. Community genetics services: report of a WHO consultation on community genetics in low- and middleincome countries. http://whqlibdoc.who.int/publications/2011/ 9789241501149_eng.pdf. 2010

Zlotogora J (2002) What is the birth defect risk associated with consanguineous marriages? Am J Med Genet 109:70-71

Zlotogora J (2005) Is there an increased birth defect risk to children born to offspring of first cousin parents? Am J Med Genet A 137A:342

Zlotogora J, Shalev SA (2010) The consequences of consanguinity on the rates of malformations and major medical conditions at birth and in early childhood in inbred populations. Am J Med Genet A 152A:2023-2028 